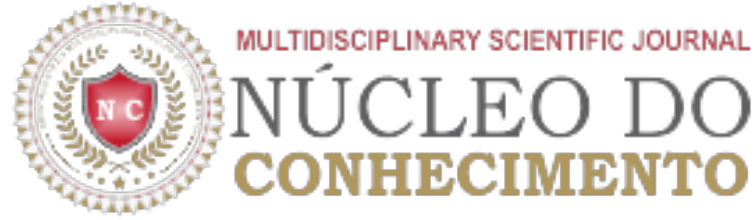

\section{Religião e Espiritualidade: Capelania Hospitalar}

\author{
SBIZERA, Carmem Lúcia Giacomelli Aoki ${ }^{[1]}$, DENDASCK, Carla Viana ${ }^{[2]}$
}

SBIZERA, Carmem Lúcia Giacomelli Aoki; DENDASCK, Carla Viana. Religião e Espiritualidade: Capelania Hospitalar. Revista Científica Multidisciplinar Núcleo do Conhecimento. Ano 03, Ed. 02, Vol. 04, pp. 144-152, Fevereiro de 2018. ISSN: 2448-0959, Link de acesso: https://www.nucleodoconhecimento.com.br/ciencia-da-religiao/capelania-hospitalar, $\quad$ DOI: 10.32749/nucleodoconhecimento.com.br/ciencia-da-religiao/capelania-hospitalar

\section{RESUMO}

A Capelania Hospitalar providencia assistência espiritual voluntária aos que assim desejarem: enfermos hospitalizados, seus familiares e profissionais da saúde. O Capelão, em seu acompanhamento e apoio, utiliza métodos que motivam pessoas enfermas e procura apoiar à manter a vida de maneira corajosa, lutando pela esperança e com fé, fortalecendo-as para o enfrentamento de suas enfermidades. O presente estudo tem como objetivo discorrer sobre a religião e a espiritualidade entre pessoas hospitalizadas, e o importante apoio espiritual oferecido por capelães hospitalares. Trata-se de um estudo de reflexão com base na literatura sobre a capelania e sua contribuição para a assistência a saúde. Na conclusiva, observouse que apesar da capelania apresentar-se como fundamental no amparo hospitalar, seja com pacientes, seus familiares e a equipe de saúde, exige uma preparação direcionada que o capelão possa atuar com eficiência.

Palavras-Chave: Religião, Espiritualidade, Capelania Hospitalar.

\section{INTRODUÇÃO}

O Ministério de Capelania Hospitalar atua na prestação da assistência espiritual voluntária aos que assim desejarem, como: enfermos hospitalizados, seus familiares e profissionais da saúde. Esta assistência dá-se através de textos de conforto baseados na Palavra de Deus, sem preconceito de raça, religião ou cor da pele ${ }^{(1-2)}$.

Nos registros bíblicos, junto aos que sofrem, Deus mostra-se, apresentando- se sempre como um Deus presente, que não os deixa em seu sofrimento. Um Deus que os auxilia, os fortalece, os anima para suportarem esses momentos difíceis ${ }^{(3)}$. 
Nas referências bíblicas de Isaías 7:14 "Por isso o Senhor mesmo lhes dará um sinal: a virgem ficará grávida e dará à luz um filho, e o chamará Emanuel"(4). E Mateus 1:23 "Eis que a virgem conceberá, e dará à luz um filho, E chamá-lo-ão pelo nome de Emanuel, que traduzido é: Deus conosco"(4). Encontrase a informação de um caminho que pode levar a esperança ao paciente. É comum os agentes da capelania fazerem suas ações de cuidados pastorais em nome de Jesus Cristo, o "Emanuel", traduzindo-se em um Deus que traz conforto, segurança e esperança ${ }^{(4)}$.

Trata-se de um desafio observado desde os primórdios do Cristianismo, como observa-se em Lucas 5:31.32: “[...] não necessitam de médicos os que estão sãos, mas sim os que estão enfermos"(4), e mais uma outra assertiva na carta universal de Tiago 5:14, na qual apresenta: "Está alguém doente entre vós? Chame os presbíteros da Igreja, e orem sobre ele"(4). São atitudes atribuídas aos cuidadores da alma humana, para atender a uma ordenação narrada, por Lucas 10:9 afirmando "[...] curai os enfermos que nela houver e dizei-lhes: é chegado a vós o Reino de Deus" "(4). Portanto, é possível observar que no Novo Testamento já registra-se a prática de cuidados aos enfermos com a assistência e o apoio espiritual. Contudo, a exemplo daquele tempo, a sociedade continua sendo um assunto muito complexo para muitos estudiosos da área.

A experiência do sofrimento no ser humano demonstra que é preciso aprender a conviver com a dor e a angústia neste momento da vida. Neste contexto de sofrimento e incertezas, é que desenvolve-se o trabalho de cuidados com a criatura, sendo o objeto desta pesquisa, com o foco na ação de capelania hospitalar $^{(5)}$. Trata-se de uma pesquisa que envolve confiança, esperança, fé e a necessidade única da presença e da ação divina na vida dos pacientes atendidos por este serviço especializados de cuidadores.

Busca-se então responder: O trabalho de apoio espiritual oferecido por capelães hospitalares realmente contribui para o restabelecimento dos pacientes hospitalizados e, principalmente para o conforto daqueles em estado terminal da doença?

Diante desta problemática e da sua consequente aceitação, desenvolve-se esta pesquisa com a finalidade de contribuir na produção do conhecimento e auxiliar na compreensão do assunto. Deus é um Deus de cura e salvação, onde nem todos os curados são salvos e nem todos os salvos serão curados.

Este estudo tem o objetivo de procurar evidenciar os benefícios para a saúde de enfermos hospitalizados, com a atuação dos capelães hospitalares, na assistência e apoio espiritual, encorajamento nos momentos de conflitos, distúrbios e dúvidas através de aconselhamento bíblico.

\section{METODOLOGIA}

Quanto ao método utilizado, a pesquisa bibliográfica tem a finalidade de colocar o pesquisador em contato com escritos sobre temas de grande alcance, neste trabalho, é fundamentalmente a questão da prática do capelão no intuito de este ser remunerado. No que diz respeito à literatura, fez-se um levantamento bibliográfico na plataforma BIREME, Biblioteca Virtual em Saúde (BVS). Como o tema não é muito aprofundado cientificamente, os critérios de inclusão estabelecidos, foram: artigos, dissertações e teses, publicados no recorte temporal de 2007 a 2017, e disponibilizados gratuitamente. Os critérios de exclusão foram: duplicidade de indexação na BVS, e manuscritos que não possuíssem relação com a proposta da presente pesquisa. 
Após a seleção e leitura de todos os materiais, fora criado o presente estudo de reflexão, que apresentará seus resultados e discussões categorizados em: Capelania hospitalar; Religião e espiritualidade; e Experiência de capelania: assistência espiritual e religiosa.

\section{RESULTADOS E DISCUSSÃO}

\section{CAPELANIA HOSPITALAR}

$\mathrm{Na}$ recente história eclesiástica do Brasil encontram-se vários registros de ações pastorais identificadas como Ministério de Capelães, dando conta que o ofício de capelania iniciou-se na Área Militar em 1858 através da Igreja Católica, sendo nominada na época por Repartição Eclesiástica e abolida em 1899. Em 1944, durante a Segunda Grande Guerra Militar Mundial o serviço foi restabelecido, renomeada por Assistência Religiosa das Forças Armadas. Ainda neste período, foi criada a Capelania Evangélica na FEB, tendo como destaque, o grande Capelão Evangélico Pastor João Filsen Soren, da primeira Igreja Batista do Rio de Janeiro, que compõe a União de Capelões e Pastores Interdenominacionais ${ }^{(6)}$.

De acordo com Bautista ${ }^{(1)}$ a "capelania hospitalar é uma organização religiosa interdenominacional com a finalidade principal de prestar assistência espiritual em instituições hospitalares".

Neste conceito, nos escritos, encontra-se uma segura referência da construção do campo conceitual de capelania, na qual observa-se que o apontamento para o cargo, a dignidade e o ofício de capelão. Tal atividade é exercida por um religioso, católico ou protestante, responsável por prestar assistência religiosa e/ou realizar culto ou missa nas instituições nas quais serve. É comum ter um local denominado capela em repartições públicas ou privadas, escolas, hospitais, quartéis, presídios, universidades e etc, onde o capelão atende às pessoas e estas podem também exercitar a sua fé é(-3) $^{\text {. }}$

Observa ainda, que é comum haver instituições que só têm capelão católico ou protestante, mas há também aquelas que comportam as duas ramificações do cristianismo, bem como fora do país há outras religiões que também têm exercido esta mesma função ${ }^{(6)}$.

É possível compreender com mais profundidade o papel do capelão ao utilizar a definição de Jung ${ }^{(7)}$, quando reforça a importância do papel do capelão enquanto facilitador da pessoa humana em situação de sofrimento. Dado autor atribuía ao capelão o papel de sujeito facilitador do encontro do homem com a sua dimensão espiritual, assim como o corpo precisa do médico, a vida espiritual da pessoa precisa do capelão.

A Capelania é uma Assistência Religiosa e Social prestada aos serviços Civis e Militares, prevista e garantida pela Constituição Federal de 1988, sob a Lei n. ${ }^{\circ}$ 6923, Art. 5 e Inciso VII: é assegurada nos termos da Lei, a prestação de assistência religiosa, na entidade civil e militar de internação coletiva ${ }^{(8)}$.

A Lei federal (n. ${ }^{\circ}$ 9.982, de 14/07/2000) dispõe sobre este inciso Constitucional, tendo esta assistência religiosa, constitucionalmente, prevista como: “Às religiões, de todas as confissões, assegura-se o acesso aos hospitais da rede pública ou privada... para dar atendimento religioso aos internados, desde que, em comum acordo com estes, ou com os familiares, em caso dos doentes que não mais estejam no gozo de suas faculdades normais" 
Ressalta-se que o Estado Brasileiro não é o responsável pela prestação de serviço religioso, tendo em observação que o Brasil é um Estado que adota a laicidade e a liberdade religiosa, sendo desta forma, a administração pública, impedida de exercer esta função ${ }^{(6)}$.

A Constituição Federal ainda assegura que:

- Esta assistência tem caráter privado e deve ser assumida pelo(s) representante(s) de cada religião/Igreja, com sua equipe;

- É de direito, tendo característica de quem está confinado (não importa o motivo);

- Todas as pessoas que encontram-se internadas, poderão, se assim o desejarem, ou a pedido da família, receber visitas de representantes habilitados, de suas respectivas instituições religiosas, de sua Religião ou Igreja, ou de outra que preferirem livremente ${ }^{(9)}$.

\section{RELIGIÃO E ESPIRITUALIDADE}

A religião pode ser definida como um sistema de crenças existente em um grupo de pessoas baseado em rituais, almejando uma relação com o Sagrado, o Divino, Deus (na cultura ocidental). Habitualmente, apoia-se em escrituras ou ensinamentos que relatam o sentido e a finalidade do mundo, o local das pessoas nele, assim como os deveres das mesmas entre si e a existência da vida após a morte. A religião, normalmente, concede uma coleção de regras que busca seguir tais normas ${ }^{(5)}$.

Determinados pacientes podem não considerarem-se religiosos, entretanto, podem estar à procura de algum significado externo, buscando respostas existenciais. Esta busca demonstra a presença da espiritualidade $^{(10)}$.

A maioria das religiões adota as crenças que desenvolvem comportamentos em relação à saúde, doença e morte. As doutrinas e ensinamentos de certas religiões apresentam orientação prática e moral para promover, manter ou restabelecer a saúde ou o bem-estar físico e emocional ${ }^{(11)}$.

A religião é uma das mais antigas manifestações do homem e para muitas pessoas, o mais importante componente de referência pessoal. Estudiosos e pesquisadores de antropologia cultural relatam que expressões religiosas existem praticamente em todos os níveis de civilização ${ }^{(12)}$.

Religiosidade e espiritualidade estão relacionadas, mas não são sinônimos. Religiosidade envolve um sistema de culto e doutrina que é compartilhado por um grupo, e, portanto, tem características comportamentais, sociais doutrinárias e valores específicos. Espiritualidade está relacionada ao transcendente, com questões definitivas sobre o significado e propósito da vida, e com a concepção de que há mais na vida do que aquilo que pode ser visto ou plenamente ${ }^{(9)}$.

Os termos espiritualidade e religião, muitas vezes, são usados de forma errada como sinônimos, mas seus significados não são os mesmos. Desta maneira, compreende-se espiritualidade como uma orientação filosófica que gera comportamentos e sentimentos de fé, amor e esperança, que proporciona um significado à vida e à relação com o transcendente, estando ou não vinculado a uma determinada religião. A espiritualidade não limita-se a aspectos dogmáticos e doutrinários. De forma diferente a religião, é a crença em uma forma divina ou sobrenatural e está ligada a uma doutrina específica, que utiliza práticas, rituais e símbolos designados a facilitar a aproximação com o transcendental ${ }^{(13)}$. 
É salientado sobre as práticas espirituais que são, na maioria das vezes, compreendidas como práticas religiosas, o que no ponto de vista científico, torna-se necessário diferenciá-las. Apesar da tendência ser incipiente, cada vez mais aparecem cursos e meios para capacitar os capelães a fim de entender a distinção entre espiritualidade e religião, assim como a forma adequada de empregar ambas na assistência ao paciente terminal. Contudo, ainda existe grande dificuldade para conceituar esta dimensão ${ }^{(11)}$.

Na compreensão do cuidado, é mais que um ato, é uma atitude, é o que abrange muito mais que um momento de atenção, de zelo e de desvelo. Representa uma atitude de ocupação, preocupação, de responsabilidade e de envolvimento afetivo com o outro, pois uma atitude perfaz uma fonte de ligação, pela qual descendem muitos atos ${ }^{(14)}$.

\section{EXPERIÊNCIA DE CAPELANIA: ASSISTÊNCIA ESPIRITUAL E RELIGIOSA}

A primeira instituição brasileira destinada ao estudo do câncer, o Instituto do Câncer Arnaldo Vieira de Carvalho, foi idealizada em 1920 pelo Dr. Arnaldo Augusto Vieira de Carvalho, então diretor da Faculdade de Medicina da Santa Casa de São Paulo ${ }^{(15)}$.

O Instituto do Câncer Arnaldo Vieira de Carvalho é uma instituição filantrópica sem fins lucrativos que tem como objetivos: Estatutário. a) promover o diagnóstico, a prevenção, a detecção e o tratamento do câncer; b) incentivar investigações científicas relativas aos problemas do câncer e dos agentes empregados no seu tratamento; c) promover cursos de especialização e aperfeiçoamento dentro de suas finalidades; d) cooperar nas campanhas de combate ao câncer, com entidades públicas ou privadas, nacionais ou estrangeiras ${ }^{(15)}$.

Em consequência do seu excelente trabalho desenvolvido junto à comunidade, o Instituto do Câncer Dr. Arnaldo foi considerado Utilidade Pública pelo Decreto Federal n..$^{\circ} 1.146$, de 13 de outubro de 1936; pelo Decreto Estadual n. ${ }^{\circ}$ 10.794, de 9 de maio de 2000; pelo Decreto Municipal n. ${ }^{\circ}$ 7.995, de 25 de fevereiro de 1969. Membro da Associação Brasileira de Instituições Filantrópicas de Combate ao Câncer

(ABIFCC), O Instituto do Câncer Dr. Arnaldo é reconhecido com Entidade Beneficente de Assistência à Saúde através do CEBAS n. ${ }^{\circ}$ SAS/MS:0204 de 28 de fevereiro de $2013^{(15)}$.

O enfermo vive num mundo de carências emocionais, de necessidades e incertezas. O papel da Capelania junto ao Instituto do Câncer Dr. Arnaldo em São Paulo, oferece aconselhamento espiritual e apoio emocional tanto ao paciente como seus familiares, e até aos profissionais da saúde. Reconhecendo e respeitando os valores e crenças individuais de beneficiários. Dispondo assim a ouvir, confortando e encorajando o doente a suportar a doença, a lutar pela vida e a ter fé em Deus e na medicina, tornando-se um coadjuvante de cura.

\section{CONCLUSÃO}

Capelania Hospitalar é uma prestação de serviço religioso, com oportunidades de levar esperança, amor e fé àqueles que encontram-se no leito, sejam adultos ou crianças, estrangeiros ou brasileiros, ricos ou pobres. É a manifestação do amor. Cumprimento do ide do Senhor Jesus, levada pelo amor, pela misericórdia e o cumprimento de Rm 12:15 que diz:" Alegrai-vos com os que se alegram; chorai com os que pranteiam". 
Desta forma, observa-se que os capelães apresentam o ponto de vista que as pessoas constituem-se muito mais do que uma dimensão física, mais que isto, uma dimensão psicológica e espiritual. Considerando não somente suas condições de saúde somadas as preocupações e problemas, mas buscam oferecer apoio e companhia aos enfermos e seus cuidadores, escutando e procurando atender suas precisões mais profundas, ajudando-os a redefinir suas vidas.

Quase todas as religiões apoiam crenças que transformem reações em momentos de estresse na saúde, em situações boas, de conforto; promovem comportamentos positivos com relação à saúde; e auxiliam as pessoas a lidar com a doença e à morte. Muitas destas doutrinas e ensinamentos oferecem orientações práticas e morais de como promover ou recuperar a saúde ou o bem-estar emocional e físico.

Concordando com os benefícios ainda causados pela espiritualidade trazida através do trabalho da capelania hospitalar, atua como uma estratégia positiva para enfrentar os problemas psicológicos causados pelas doenças, reduzindo significativamente o estresse causado pelo tratamento médico.

O Capelão em seu acompanhamento e apoio utiliza métodos que motivam pessoas enfermas, acamadas e as conduz a manter a vida de forma corajosa, lutando pela esperança e com fé, fortalecendo-as para o enfrentamento de suas enfermidades. Estudos indicam que a prática da oração contribui para aprimorar o senso de objetividade, atenção, aprendizagem e memória, pois nestes momentos as áreas cerebrais responsáveis por estas capacidades são ativadas.

\section{REFERÊNCIAS}

1. Bautista M. Com Los que sofren. Buenos Aires, San Pablo; 1994.

2. Silva DG. Capelania Hospitalar e a Terapia da Enfermidade: Uma Visão Pastoral. Universidade Presbiteriana Mackenzie, Programa de Pós-Graduação Em Ciência da Religião, São Paulo; 2010.

3. O que é Pastoral da Saúde. São Paulo: Paulinas; 2000.

4. Bíblia. A Bíblia Sagrada: Antigo e Novo Testamento. Tradução de João Ferreira de Almeida. Edição rev. e atualizada no Brasil. Brasília: Sociedade Bíblia do Brasil; 1969.

5. Koening HG. Espiritualidade no cuidado com o paciente: por quê, como, quando e o quê. São Paulo: FE Editora Jornalística Ltda; 2005.

6. Hoepfner D. Fundamentos Bíblico-Teológicos da Capelania Hospitalar: Uma contribuição para o cuidado integral da pessoa. [Dissertação] Escola Superior de Teologia, São Leopoldo; 2008.

7. JUNG CG. Psicoterapia e direção espiritual. Petrópolis: Vozes; 1988.

8. Presidência da República. Casa Civil. Subchefia para Assuntos Jurídicos; 2000.

9. Princípio de compaixão e cuidado. 3. ed. Petrópolis: Vozes; 2001.

10. Penha S. Significado de Espiritualidade para enfermagem em cuidados intensivos. Texto Contexto 
Enferm. 2012; 21(2).

11. Espiritualidade: um caminho de transformação. Rio de Janeiro: Sextante; 2001.

12. Saad M, Masiero DB, Linamara R. Espiritualidade Baseada em Evidências. Acta Fisiátrica. 2001; $8(3)$.

13. Gentil RC, Guia BPG, Sanna MC. Organização de serviços de capelania hospitalar: um estudo bibliométrico. Esc. Anna Nery. 2011.

14. Ministério da Saúde (BR). Departamento Nacional de Saúde, Divisão de Organização Hospitalar. Livro: História Evolução dos Hospitais. Rio de Janeiro,;1965.

15. Levin J. Deus, fé e saúde: Explorando a conexão espiritualidade-cura. São Paulo: Editora PensamentoCultrix Ltda.; 2003.

16. Instituto de Câncer Dr. Arnaldo. Quem Somos. São Paulo; 2016.

11] Teóloga. Licenciada em História. Docente de História e Geografia do Curso de Bacharel em Teologia na Universidade Santanna em São Paulo - SP. Mestranda em Ciências da Religião pela Universidade Presbiteriana Mackenzie.

${ }^{[2]}$ Teóloga. Doutora em Psicanálise Clínica. Especialista em Pesquisas de Mercado e Pesquisas voltadas à área da Saúde. Diretora da Revista Científica Multidisciplinar.

\section{PUBLIQUE SEU ARTIGO CIENTÍFICO EM:}

https://www.nucleodoconhecimento.com.br/enviar-artigo-cientifico-para-submissao 